\title{
Use of Categorical Regression Model for Optimization of Interventions in the Information Labor Market System for the Youth
}

\author{
Enida Kume
}

"Alekxander Moisiu" University, Durrës, Albania

Email: enidak@hotmail.it

\author{
Doi:10.5901/jesr.2016.v6n1p109
}

\section{Abstract}

The behavior of youth to the labor market information is the product of the action and interaction of various factors, psychological, social and economic. In Albania it is estimated that only about $49.6 \%$ of young people express interest and consider this information useful. Young people are selective to channel information. The reliability valuation for the information that published by public institutions, labor offices, electronic and print media or non-public institutions, is relatively low. Young people evaluate the credibility of the information they receive from friends (96.7\%) and / or from family (79.8\%). Results of the categorical regression model used to explain the behavior of young people to the labor market information, showed that have a statistically significant affect of employment status $(P<0.01)$, education level $(P<0.01)$ and age $(P<0: 05)$ on the formation of this behavior. The gender and family economic level do not have a statistically significant effect $(P>0: 05)$. Referring to the values of psycho-social and economic factors, categorical regression model, modeling the behavior of young people to the labor market information, through the generation of four groups, corresponding to the four levels of youth perception of this need.

Keywords: information, labor market, young people

\section{Introduction}

The International Labour Organization (ILO) has noted that the 0 employment of young people in Albania remains a challenge. According to ILO, the development dynamics of this challenge highlights the need to treat it, thereby addressing, at the same time, supply and demand in the labor market.

A special role, in order to succeseed in this multi dimension challenge, it is played by government agencies, institutions and organizations of employers and workers. These institutions are responsible for identifying the needs of the labor market and assessing the technical requirements for the professional formation of youth in accordance with this labor market requests. These are among the key institutions that supply the information channels for the needs and requirements of the labor market for young people (CRD, 2003).

In developing countries, which do not have sufficient experience in the management of labor market problems, the information service about market offerings is a priority that must be supported and developed (February, A. et al. 2010) . When this information targets young jobseekers, policies and support programs should be developed keeping permanently into account the fact that the perception of young people to quality, reliability and value of information flowing in different channels of information is different from that of other active labor forces. (CRD, 2003; Dalip, M. 2011; Shurti, A. et al. 2010).

Based on the perceptions of young people about the importance of information on offerings of the labor market and their evaluation of the quality of this information depending on its source, the study aims to build a categorical regression model that can be used as an instrument for identifing ways to be followed for capacity development of the information service of young people to the labor market offerings.

\section{Survey Methodology}

\subsection{The purpose of the study}

The purpose of this paper is to develop a method that can be used to quantify the perception of young people about the importance of labor market information and its quality, depending on the information source, gender, age, level of 
education, employment status of the juvenile and family economic level. The quantitative assessment of the level of these perceptions among young people who live in different urban areas of Albania is part of the aims of this paper.

\subsection{The objective of the study}

The objectives of the paper are:

Identification of factors that influence the formation of the behavior of young people to the need for information, relevance and credibility of information on employment opportunities and from which channels this information derives. Modeling the reliability to the information in the form of a categorical regression model, which can be used as an instrument that can assist policies elaboration and middle term development programs for the information system of labor market opportunities for young people.

\section{Research hypothesis}

The study had as objective to verify the overthrew research hypotheses:

$\mathrm{H}_{1}$ : Youth evaluation for the reliability and information value varies depending on the institution that produces this information.

$\mathrm{H}_{2}$ : The behavior of young people to the labor market information varies depending on gender, age, level of education, their employment situation and family economic level.

\section{Material and Methods}

The data for completion of this study were taken by interviewing young people who live in different city of the country. The questionnaire contained closed questions. The answers generated variables measured on Likert scale (Bertram, D. 2010).

Respondents were asked to express their evaluation approach according to the level: 1-insignificant, 2-less important, 3- important and 4-very important. The questionnaire also contained questions with some alternative responses, for which the respondents were required to make only one choice or more than one choice depending on the question.

For the quantitative assessment of youth perception level about the importance of information for labor market opportunities were calculated weighted averages of the values of the dependent variable (assessment of information), expressed in Likert scale, for all levels of psycho-social and economic factors taken into analysis. The behavior of young people to the need for further information on labor market opportunities, based on their perceptions of the importance and quality of information for this market, it is the product of the action and interaction of various factors psychological, social and societal (Kume E., 2013).

The study on the effects of these factors was conducted according to a Categorical Regression Model (Meulman and Heiser, 2004).

The dependent variable "value of information" and the independent variables "age", "level of education" and "the economic situation of the family" are categorical variables measured in Likert scale (ordinal scale), while "gender" and " employment status" are independent categorical variables measured in nominal scale. Since the categorical variables are quantitatively expressed, the squared coefficient of the correlation between the dependent variable and independent variables group, obtains the maximum value (Kooij and Meulman, 1997; Meulman et al.2002).

The below social and economic factors were taken into account for the establishment of the Categorical Regression model:

1. Interviewee Gender

2. Age (15-20 years, $21-25$ years, $26-30$ years)

3. Level of education (basic education, secondary vocational education, general secondary education, university education and postgraduate education)

4. Employment status (Unemployed - students, Unemployed - seeking to be employed, Unemployed - who's not seeking to be employed, Employed - in the private sector (full-time), Employed - in the private sector (part time), Employed - in the public sector (central government), Employed - in the public sector (local government), Employed in other public sectors, Emplyed - in NGO's, Self-employed)

5. Economic family level (Low - average monthly income $<30,000$ lek, Medium - average monthly income 30000- 
50000 lek, High - average monthly income $>50000$ lek)

\section{Sample Description}

641 young people, choosen randomly, from the cities of Shkodra, Tirana, Durres, Elbasan, Berat, Vlora and Saranda were interviewed. Approximately, $51.95 \%$ were girls and $48.05 \%$ boys. Youth aged $16-20$ years accounted for about $26.4 \%$ of the sample, $21-25$ years approximately $48.5 \%$ and $26-30$ approximately $25.1 \%$.

About $9 \%$ of them completed basic education, $14.8 \%$ secondary vocational education, $58.5 \%$ secondary general education, $16.5 \%$ university education and $1.7 \%$ postgraduate education. About $27.1 \%$ belonged to families with low economic level, $59.6 \%$ to medium economic level and $13.3 \%$ were from families with high economic level. The sample structure regarding youth employment status is given in Figure no. 1.

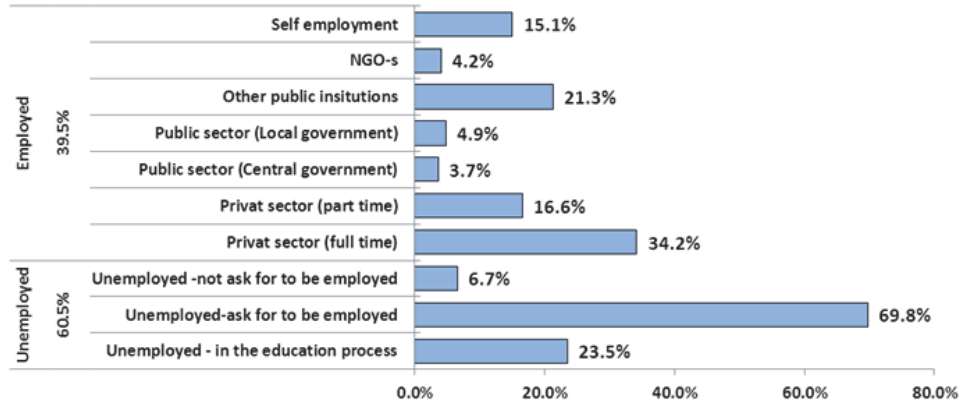

Figure no. 1. Sample structure regarding the employment status

\section{Results and estimation}

\subsection{Results}

About $49.6 \%$ of the respondents expressed that it was important to get information about the labor market, while about $35.2 \%$ considered it unnecessary and $15.2 \%$ did not express any opinion. The selection of source information is variegated. Among them the most preferable is getting information from friends / buddies or family (respectively $74 \%$ and $52 \%$ ) and less preferably is the Internet and electronic media (ie $2 \%$ and $6 \%$ ).

Only, about $39 \%$ of youth were aware of the existence of a public institution (office work) that provides information on employment, while only about $21 \%$ of the respondents selected that as a source of information (Figure no. 2).

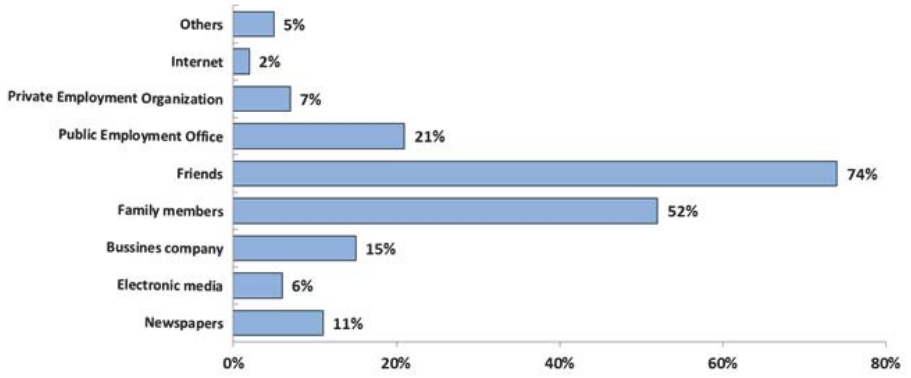

Figure nr. 2. Ways of informing young people about the labor market opportunities

The perception evaluation, among young people, for the credibility of the information received from various channels of 
information, varies sensitively depending on the channel (Figure no. 3).

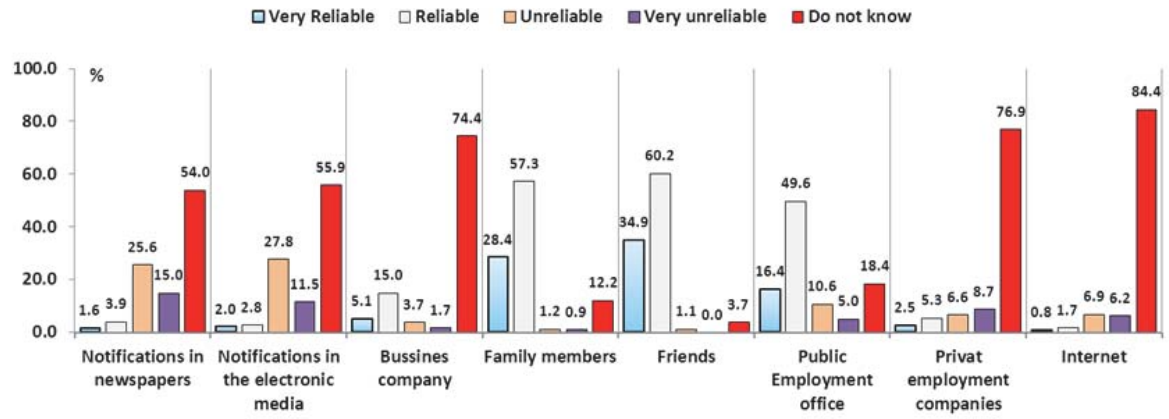

Figure no. 3. Youth perception about source information credibility

The results of the quantitative assessment for the level of perception among young people, about the importance of labor market opportunities information is given in Figure no. 4.

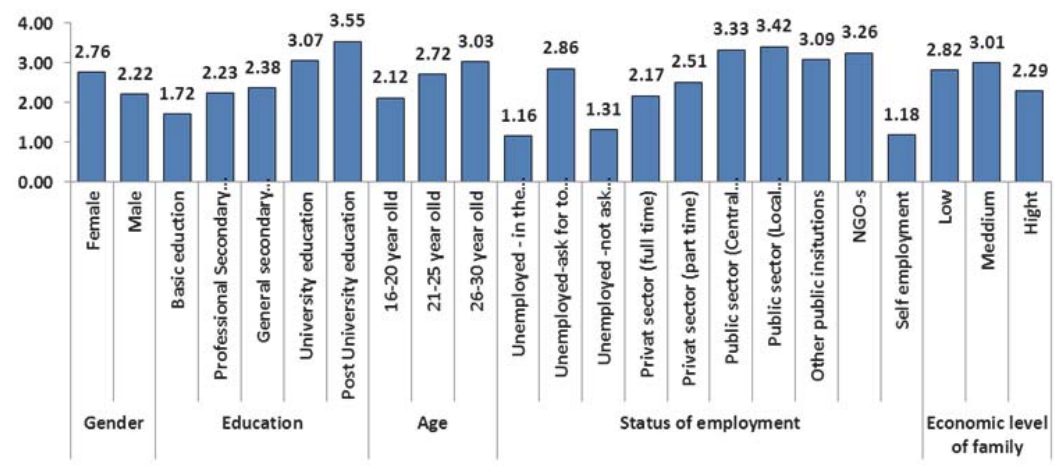

Figure no. 4. The average weighted values that reflect the level of perception of young people about the importance of information, corresponding to their demographic, social and economic.

Table no. 1 provides the estimations for the partial regression coefficients of categorical regression model, corresponding to the analysed.

The optimal value of the categorical variables assessed by the categorical regression model are shown in Table no. 2. Their graphic presentation, in a single shaft, is given in Diagram No. 1.

Table 1. Evaluation of the independent variable coefficients in the categorical regression model

\begin{tabular}{|l|c|c|c|}
\hline \multirow{2}{*}{ Coefficients } & \multirow{2}{*}{ df } & \multicolumn{2}{|c|}{ Standardized coefficients } \\
\cline { 3 - 4 } & & Beta & Std. Error \\
\hline Gender & 1 & $-0.012^{\text {NS }}$ & 0.065 \\
\hline Age & 2 & $0.148^{*}$ & 0.025 \\
\hline Educational level & 4 & $-0.385^{*+}$ & 0.096 \\
\hline Employment status & 11 & $0.634^{* *}$ & 0.106 \\
\hline Economic level of family & 2 & $-0.412^{*+}$ & 0.099 \\
\hline
\end{tabular}

${ }^{\mathrm{NS}}$ non significant, ${ }^{*} \mathrm{P}<0.05,{ }^{\text {** }} \mathrm{P}<0.01$ 
Table 2. The optimal values of the independent variables estimated by the categorical regression model.

\begin{tabular}{|c|c|c|}
\hline Variables & Frequency & Optimum value \\
\hline \multicolumn{3}{|l|}{ Quantitative Assessment of information } \\
\hline Unimportant & $96(14.97 \%)$ & -1.4 \\
\hline Few important & $156(24.35 \%)$ & 0.12 \\
\hline Important & $217(33.85 \%)$ & 1.0 \\
\hline Very important & $172(26.83 \%)$ & 3.21 \\
\hline \multicolumn{3}{|l|}{ Gender } \\
\hline Male & $311(51.48 \%)$ & -0.01 \\
\hline Female & $330(48.52 \%)$ & 0.87 \\
\hline \multicolumn{3}{|l|}{ Age } \\
\hline $15-20$ years & $170(26.52 \%)$ & -0.34 \\
\hline $21-25$ years & $311(48.52 \%)$ & 0.63 \\
\hline $26-30$ years & $160(24.96 \%)$ & 1.21 \\
\hline \multicolumn{3}{|l|}{ Educational level } \\
\hline Basic education & $57(8.89 \%)$ & -0.74 \\
\hline Professional Secondary education & $92(14.35 \%)$ & -0.13 \\
\hline General Secondary education & $375(58.50 \%)$ & 0.17 \\
\hline University education & $106(16.54 \%)$ & 1.76 \\
\hline Post university education & $11(1.72 \%)$ & 3.45 \\
\hline \multicolumn{3}{|l|}{ Employment status } \\
\hline Unemployed - in the education process & $91(14.20 \%)$ & -0.85 \\
\hline Unemployed-ask for to be employed & $271(42.28 \%)$ & 1.02 \\
\hline Unemployed -not ask for to be employed & $26(4.06 \%)$ & -2.12 \\
\hline Private sector (full time) & $86(13.42 \%)$ & -0.29 \\
\hline Private sector (part time) & $42(6.55 \%)$ & 0.32 \\
\hline Public sector (Central government) & $9(1.40 \%)$ & 2.87 \\
\hline Public sector (Local government) & $12(1.87 \%)$ & 3.06 \\
\hline Other public institutions & $54(8.42 \%)$ & 2.08 \\
\hline NGO-S & $11(1.72 \%)$ & 2.12 \\
\hline Self employment & $39(6.08 \%)$ & -1.56 \\
\hline \multicolumn{3}{|l|}{ Economic level of family } \\
\hline Low & $174(27.1 \%)$ & -0.41 \\
\hline Medium & $382(59.6 \%)$ & 2.01 \\
\hline Hight & $85(13.3 \%)$ & -0.17 \\
\hline
\end{tabular}

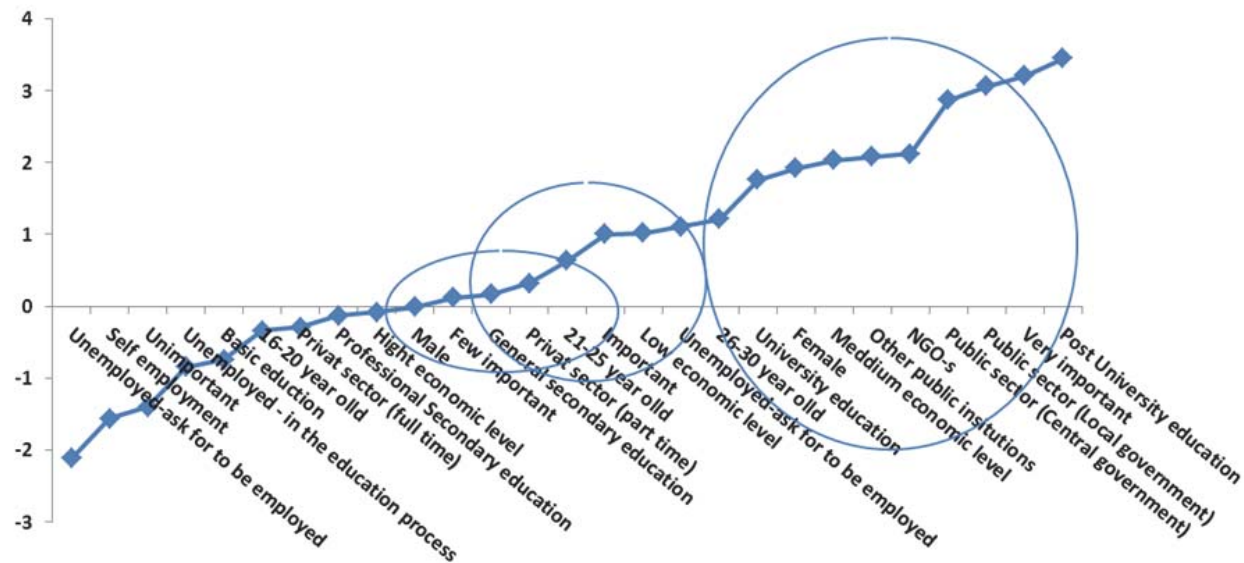

Diagram 1. Presentation of the optimal values of the independent variables on a single shaft 


\subsection{Estimation}

The fact that only about $49.6 \%$ of young people have expressed interest and have considered the need for information for labor market opportunities, important, shows that, in general, the channels of information for these opportunities are not effective.

Meanwhile, information on labor market is the key, in order to provide individualized employment counseling and job search assistance (Corbanese and Rosas, 2009).

The low preferences of young people for public or private formal channels of information, such as emplyement offices, print and electronic media etc., compared with the appreciation that they express for the information through relatives / friends and family, identify the fact that in Albania the information system capacities are small and their impact on solving the problems of employment for young people does not have a great impact. Such finding is almost identical to those given in other studies of this nature, in Albania, $75 \%$ of young people prefer information from relatives (QKZH, 2003); 79\% from personal knowledge (Partner-Albania, 2010); only 19\% of respondents are beneficiaries of the employment services offered by the employment offices (Hyka, p 2012) etc.

Referring to this situation we can affirm that, notwithstanding the declared investments, which have tried to increase the capacity of formal institutions, especially public ones, to inform young people about labor markets needs, to the demands of this market with respect to youth technical and professional performances etc .., the results are far from the objectives stated in the National Plan of Action for youth Employment, 2007-2013 (MPCSSHB, 2007).

The perception about the reliability of information is one of the main factors affecting the attitude of young people to formal and informal institutions providing labor market information.

Young people highly rely on the information received from friends / relatives $(95.1 \%)$ or family (85.7\%). The information provided by electronic media, newspapers and employment offices are considered unbelievable or unreliable, respectively by $39.3 \%, 40.6 \%$ and $15.6 \%$. of the young people interviewed. This opinion is highly expressed in young people with university or postgraduate education. The fact that, in a considerable percentage, young people do not express any opinion on the level of credibility for the information provided by public employment offices (35.6\%), private companies (76.9\%), electronic media (55.9\%), newspapers (54.0\% ) and internet (84.4\%), indicates that the albanian information system for labor market opportunities has essential deficiencies.

The perception of youth for the value and reliability of information communicated via the Internet, stands in particular. This is a significant indicator that shows that, although considerable resources were mobilized for the use of IT in order to increase capacities in the employment services, as provided for in the relevant policies and documents (Employment Services Strategy, 2005-2009. P.10; Employment Sector Strategy, 2007-2013, p.20), the desired results are far from the setted objectives.

The low level of credibility for labor market information continues to be an almost unchaged behavior features of Albanian youth. Similar studies, conducted earlier, have shown almost the same behavior and level of perception of young people for the information reliability, depending on its source (QKZH, 2003; Partner-Albania, 2010, EMA, 2012). The conservatism that characterizes this behavior is an indicator that reinforces the need for reconsidering the labor market information system for young people.

The quantitative assessment on the level of perception among young people, about the importance of information on labor market opportunities, corresponding to their different economic and psychosocial situations, show that: (i) women have greater interest for this information, (ii) the interest to be informed increases with growth and educational level, (iii) greater interest have young people employed in public institutions and unemployed jobseekers, (iv) the family economic level conditions youth interest for labor market information.

These data can be used as guiding information for conceiving the interventions that can / should take place for young people labor market information system. Despite this, since in calculating these evaluations the below facts were not taken into account,:

(a) economic and psycho-social factors have different impact on the perception formation and,

(b) the quantitative value of this perception is the resultant of the action and interaction of these factors,

the results obtained from the Categorical Regression can be used, as the base, in order to make possible the rigorous scientific formulation of interventions that should take place in the current system of information.

The statistical analysis showed that the coefficient of the multiple correlation, which reflects the relationship between the dependent variables, the quantitative assessment of the importance of information and the independent variables, is statistically significant $\left(R=0.613, p<0.01, R^{2}=0.375\right.$ ). Thus, about $37.5 \%$ of general variances, that reflects the changes in the level of perception of young people about the importance of information for labor market opportunities, 
is a consequence of the action and interaction of economic and psycho-social factors, which are the subject of this study.

Tables No. 1 data show that the impact of gender and family economic level, as part of the multiplying effects of all factors involved in the categorical regesionit model is not statistically significant $(P<0.05)$. Age, educational level and employment status are factors with statistically significant influention. Referring to the $\beta$ coefficient values, the ranking of these factors according to their importance on the perception formation among young people is: employment status $(\beta=0.504)$, age $(\beta=0.148)$, and level of education $(\beta=-0.385)$.

Based on the optimal values of the categorical variables (Table no.2) and the graphic presentation in a single shaft (diagram No. 1), we can form several youth groups, which are distinct from each other because of their level of perception on the need for information:

(i) Young people who consider unimportant the information on labor market opportunities. Parts of this group are: young men, aged 16-20 years old, with basic education or vocational schools, from families with high level of economic growth. Members of this group are young unemployed, who are not seeking employment, young people who attend school, self-employed or full time wokers of the private sector.

(ii) Young people who consider poorly important the information on labor market opportunities. This group includes: young men, aged 21-25 years old, with general secondary education, part-time workers in private sector and, in general, belonging to families with high economic level.

(iii) Young people who consider important the information on labor market opportunities. Parts of this group are: young people aged 21-25 years, of both sexes, unemployed job seekers, from families with low economic level.

(iv) Young people who consider very important the information on labor market opportunities. This group includes: young women, age 26-30, from families with middle economic level, who have a university education or postgraduate and who are working in the public sector or NGOs.

The above groups show that the behavior of young people to the need for information on labor market is complex. The action of various factors, psycho-social and economic in its formation can be explained only if they are studied by considering them at the same time, all together. The above results show that the categorical regression model is one of the instruments that can be used for this purpose.

The results obtained from the categorical regression model identify the fact that the transmission of information to young people, in particular from public institutions, regardless and bypassing their different status, psychosocial and economic features of different groups of young people, is one of the factors inciting their indifference to this information.

These results, in particular the data about the youth grups features, which are generated by the categorical regression model, are qualitative information that can be successfully used to develop policies and direct interventions on youth labor market information system and to improve the employment system services.

\section{Conclusions}

It is estimated that in Albania only about $49.6 \%$ of young people express interest and consider necessary labor market information.

Young people are selective to channel information. Their assessment of the reliability of the information depends on the institution that transmits this information. Confidence in the information provided by public institutions, employment offices, electronic and written media or non-public institutions, is relatively low. Young people trust more the information that they receive from friends / relatives (96.7\%) and / or family (79.8\%).

The results of the categorical regression model, which was conceived to explain the behavior of young people toward labor market information, show that the employment status $(P<0: 01)$, education level $(P<0: 01)$ and age $(P$ $<0: 05)$, have a statistically significant impact in the formation for this behavior. Gender and family economic level effect in the overall variance of perception value of young people on the need for labor market information are not statistically proved $(\mathrm{P}<0.05)$.

Referring to various values of psycho-social and economic factors, by using the categorical regression model we can achieve to model the behavior of young people toward labor market information. The categorical regression model generates four different groups, in which are included young people who have fundamental behavior differences toward this information.

By taking into account the pattern of youth behavior, conceived by using the results of the categorical regression model, we can increase the opportunities for developing policies and guidance for effective interventions to the labor market information system and improving the employment system services. 


\section{References}

Aggelopoulos, S., Arabatzis, G. 2010. European Union Young farmers Program: A greek case study.

Bertram, D. 2010 Likert Scales. CPSC 681 - Topic Report (available in: http://poincare.matf.bg.ac.rs/ -kristina/topic-dane-likert.pdf)

Dalipi, M. 2011. Papunesia ne rradhet e te rinjve . E301. Ekonomiks pune

EMA (European Mouvement Albania) 2012. Studim Pjesa I: Një vështrim mbi programet e nxitjes së punësimit në Shqipëri, Nëntor 2012. www.em-al.org

Kooij, A.J. Meulman,J.J. 1997. Multiple Regression and Optimal Scaling using alternating least squares. In: Softstat '97, Eds., W.Bandilla and E.Faulbaun. Stuttgart:Luicius and Luicius, pp.99-106

Kume, E. 2013. Study of Factors Affecting Attitude Formation Towards Labor Market Offer of Albanian Youth in Urban Areas. Mediterranean Journal of Social Science. Vol. 4. No. 2, p.337-346

Meulman, J., Heiser, W. 2004 SPSS Categories 13.0. Chicago:SpSS,Inc.

Partner-Albania. 2010

Pastore, F. 2007. Employment and Education Policy for Young People in the EU: What Can New Member States Learn from Old Member States?

PAPR - Plani i aksionit për punësimin e të rinjve, 2007-2013. Ministria e Punës, Çështjeve Sociale dhe Shanseve të Barabarta, Tiranë, Nëntor, 2007

QKZH., 2003. Studim mbi Integrimin e Rinisë në Tregun e Punës: Pengesat dhe Vështirësitë

MPÇSShB, 2005. Strategjia e Sherbimeve të Punesimit, 2005-2009. p.10

MPÇSShB, 2007. Strategjia Sektoriale e Punesimit, 2007-2013, p.20

Shkurti, A. 2010. Shërbimet e këshillimit të karrierë: Shembuj dhe këshilla praktike. Udhëzues per hartuesit e shërbimeve. Ministria e Punes

Valli' Corbanese, Rosas., G. 2009. Udhëzues për hartimin, monitorimin dhe vlerësimin e programeve novatore aktive të tregut të punës që targetojnë individë në rrezik përjashtimi nga tregu i punës. ILO Subregional Office for Central and Eastern Europe guide I promotion of employment / vocational training / counselling / target group / vulnerable groups 13.01.3 